\title{
COVID-19 vaccination intention and vaccine characteristics influencing vaccination acceptance: a global survey of 17 countries
}

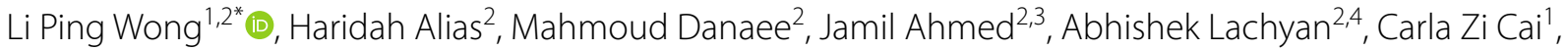

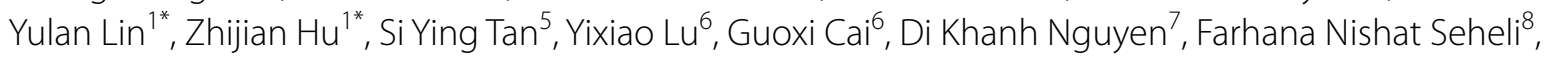
Fatma Alhammadi ${ }^{9}$, Milkar D. Madhale ${ }^{10}$, Muditha Atapattu ${ }^{11}$, Tasmi Quazi-Bodhanya ${ }^{12}$, Samira Mohajer ${ }^{13}$, Gregory D. Zimet ${ }^{14}$ and Qinjian Zhao ${ }^{15}$

\begin{abstract}
Background: The availability of various types of COVID-19 vaccines and diverse characteristics of the vaccines present a dilemma in vaccination choices, which may result in individuals refusing a particular COVID-19 vaccine offered, hence presenting a threat to immunisation coverage and reaching herd immunity. The study aimed to assess global COVID-19 vaccination intention, vaccine characteristics influencing vaccination acceptance and desirable vaccine characteristics influencing the choice of vaccines.
\end{abstract}

Methods: An anonymous cross-sectional survey was conducted between 4 January and 5 March 2021 in 17 countries worldwide. Proportions and the corresponding 95\% confidence intervals (CI) of COVID-19 vaccine acceptance and vaccine characteristics influencing vaccination acceptance were generated and compared across countries and regions. Multivariable logistic regression analysis was used to determine the factors associated with COVID-19 vaccine hesitancy.

Results: Of the 19,714 responses received, $90.4 \%$ (95\% Cl 81.8-95.3) reported likely or extremely likely to receive COVID-19 vaccine. A high proportion of likely or extremely likely to receive the COVID-19 vaccine was reported in Australia (96.4\%), China (95.3\%) and Norway (95.3\%), while a high proportion reported being unlikely or extremely unlikely to receive the vaccine in Japan (34.6\%), the U.S. (29.4\%) and Iran (27.9\%). Males, those with a lower educational level and those of older age expressed a higher level of COVID-19 vaccine hesitancy. Less than two-thirds (59.7\%; 95\% Cl 58.4-61.0) reported only being willing to accept a vaccine with an effectiveness of more than $90 \%$, and $74.5 \%$ (95\% Cl 73.4-75.5) said they would accept a COVID-19 vaccine with minor adverse reactions. A total of 21.0\% (95\% Cl 20.0-22.0) reported not accepting an mRNA vaccine and 51.8\% (95\% Cl 50.3-53.1) reported that they would only accept a COVID-19 vaccine from a specific country-of-origin. Countries from the Southeast Asia region reported the highest proportion of not accepting mRNA technology. The highest proportion from Europe and the Americas would only accept a vaccine produced by certain countries. The foremost important vaccine characteristic influencing

\footnotetext{
*Correspondence: huzhijian@fjmu.edu.cn; wonglp@ummc.edu.my;

yulanlin@fjmu.edu.cn

1 Department of Epidemiology and Health Statistics, Fujian Provincial Key

Laboratory of Environment Factors and Cancer, School of Public Health,

Fujian Medical University, Fuzhou 350122, Fujian, China

Full list of author information is available at the end of the article
}

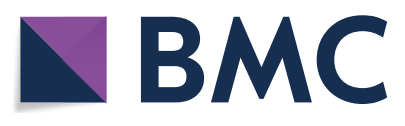

(c) The Author(s) 2021. Open Access This article is licensed under a Creative Commons Attribution 4.0 International License, which permits use, sharing, adaptation, distribution and reproduction in any medium or format, as long as you give appropriate credit to the original author(s) and the source, provide a link to the Creative Commons licence, and indicate if changes were made. The images or other third party material in this article are included in the article's Creative Commons licence, unless indicated otherwise in a credit line to the material. If material is not included in the article's Creative Commons licence and your intended use is not permitted by statutory regulation or exceeds the permitted use, you will need to obtain permission directly from the copyright holder. To view a copy of this licence, visit http://creativecommons.org/licenses/by/4.0/. The Creative Commons Public Domain Dedication waiver (http://creativeco mmons.org/publicdomain/zero/1.0/) applies to the data made available in this article, unless otherwise stated in a credit line to the data. 
vaccine choice is adverse reactions (40.6\%; 95\% Cl 39.3-41.9) of a vaccine and effectiveness threshold (35.1\%; $95 \% \mathrm{Cl}$ 33.9-36.4).

Conclusions: The inter-regional and individual country disparities in COVID-19 vaccine hesitancy highlight the importance of designing an efficient plan for the delivery of interventions dynamically tailored to the local population.

Keywords: COVID-19 vaccine, Vaccination intention, Vaccine characteristics, Vaccination acceptance, Vaccine choice

\section{Background}

Coronavirus disease 2019 (COVID-19), firstly reported in December 2019 [1], was declared a global pandemic by the World Health Organisation (WHO) on March 11, 2020 [2]. The novel coronavirus proliferated across the globe and has since become the greatest public health crisis the world has faced in over a century [3]. One year into the pandemic, as of early March 2021, there have been over 100 million global cases and over 2 million deaths reported [4]. Mass COVID-19 vaccination rollout is a public health top priority to mitigate the pandemic. The pandemic has motivated a global race in vaccine development initiatives which started as soon as the genetic sequence of SARS-CoV-2 was revealed. As of 2 March 2021, according to the WHO's draft landscape of COVID-19 candidate vaccines, there were 76 candidate COVID-19 vaccines in clinical development and 182 in the preclinical evaluation stages [5]. Of significant importance to pandemic control, seven vaccines have been approved for full use and six for early or limited use across various countries as of 3 April 2021.

Vaccine hesitancy is a growing threat to global health security and the WHO named vaccine hesitancy as one of the top ten threats to global health in 2019 [6]. Despite the catastrophic impact of the pandemic and the enormous global effort to develop a vaccine as rapidly as possible, the COVID-19 vaccine is not spared from scepticism and hesitancy. Recently, COVID-19 vaccine hesitancy has been a subject of intense global interest. It is well known that the accelerated speed of the development as well as the fact that the vaccine is new has caused fear of its unknown safety and long-term side effects. The duration of protection of the current COVID-19 vaccines is also unknown. As the coronavirus mutates rapidly, new vaccines may need to be developed to combat more mutant strains of the coronavirus. Given the uncertainties surrounding the duration of protection and the possible need to be vaccinated against COVID-19 annually, similar to the seasonal flu vaccination, people may have an increased level of hesitancy towards a COVID-19 vaccination.

An important source of COVID-19 vaccine hesitancy that is not yet understood is the availability of various COVID-19 vaccines with different characteristics. Due to the global COVID-19 vaccine shortage, the public in many countries may not be able to choose one vaccine over another. People may be unwilling to get vaccinated if the COVID-19 vaccine offered in their country's vaccination program is not their vaccine of choice. The current COVID-19 vaccines available differ in various characteristics such as level of efficacy for prevention of symptomatic disease, administration doses, manufacturing platforms, and effectiveness against virus variants [7]. Vaccine efficacies ranging from 50 to $95 \%$ have been reported [8]. It is unclear whether news headlines reporting certain COVID-19 vaccines offering greater than $90 \%$ effectiveness against COVID-19 while other vaccines having results of just over $50 \%$ effectiveness would influence a person favouring a certain vaccine over another.

In regards to administration doses, some of the COVID-19 vaccines will require two doses, while others just require one dose. The diverse manufacturing platforms of the COVID-19 vaccines also pose a challenge in vaccine choice. The public may lack confidence in vaccines developed using the messenger RNA (mRNA) technology over the traditional inactivated virus and recombinant protein platforms. The COVID-19 vaccines are being developed and produced by different manufacturers around the world. The country of manufacture of the COVID-19 vaccine may also be associated with hesitancy [9]. Distrust in vaccines from a specific countryof-origin has been reported [10-12]. The unprecedented speed of development and the rapid rollout of COVID-19 has also led some to believe, without evidence, that this is a result of skipping essential steps or being politically driven, leading to distrust in vaccines [11,13-15].

The availability of several COVID-19 vaccines presents uncertainty on which vaccine to choose. Unwillingness to get vaccinated due to not favouring the COVID-19 vaccine offered in the country vaccination program can be the reason people refuse vaccination and may present a threat to achieving herd immunity. Therefore, understanding the vaccine characteristics influencing vaccine acceptance and choice of vaccine are important to inform effective strategies to improve vaccine uptake and coverage. A large-scale global study to evaluate the diverse COVID-19 vaccine characteristics influencing vaccination acceptance after the vaccine is available to 
the public is lacking. This multi-country survey aimed to assess (1) COVID-19 vaccination intentions and (2) vaccine characteristics influencing vaccination acceptance and choice. The vaccine characteristics investigated in this study are important factors expected to be associated with COVID-19 vaccine hesitancy (level of effectiveness, administration doses, adverse reactions, duration of protection, the new mRNA manufacturing platform, and country of the vaccine manufacturer).

\section{Methods}

\section{Study design and participants}

A purposive sample of researchers from various countries across all regions worldwide from the researchers' academic linkages was invited to participate in this global survey. Researchers from a total of 17 countries responded to the invitation. Hence, a multi-country, cross-sectional survey was carried out in 17 countries using an online self-administered questionnaire during the period from 4 January to 6 March 2021. The 17 countries were grouped into six WHO regions: (1) African Region: South Africa; (2) Region of the Americas: United States of America; (3) South-East Asia Region: Bangladesh, India, and Sri Lanka; (4) European Region: Norway, and the United Kingdom; (5) Eastern Mediterranean Region: Iran, Pakistan, Somalia, and the United Arab Emirates; and (6) Western Pacific Region: Australia, China, Japan, Malaysia, Singapore, and Vietnam. The inclusion criteria were that individuals had to be 18 years or older, a citizen of the included countries, have not yet been vaccinated against COVID-19, and provide informed consent online.

A convenience sampling method was used in data collection. The sample size was calculated for each country using the formula: $n=\mathrm{Z}^{2} \mathrm{P}(1-\mathrm{P}) / \mathrm{d}^{2}$ [16]. Using a 0.05 margin of error with a $95 \%$ confidence intervals $[C I]$ and $50 \%$ response distribution, the calculated sample size was 384 . The sample size was multiplied by the predicted design effect of two to account for the use of convenience sampling and an online survey [17]. Hence, the minimum survey sample size for each country was set to 768 $(384 \times 2)$ participants.

The collaborators of all 17 countries were provided detailed information on the study and data collection strategies. Collaborators were informed as much as possible to distribute the survey link to the public of diverse cities in their country. Data collection was carried out using Google Forms and Qualtrics, distributed on social media platforms (repeated posting on Facebook, Twitter, WhatsApp and WeChat), online websites, and blogs in their countries. To increase response rates, a note encouraged survey respondents to share the survey links with their contact lists upon completion of the survey.

\section{Measures}

Participants completed an online questionnaire (Additional file 1) on their (1) demographic background, (2) COVID-19 vaccination intention, (3) vaccine characteristics influencing acceptance, and (4) factors influencing the choices of COVID-19 vaccine. The questionnaire was developed in English. The native language option of the questions was available for surveys carried out in China, Vietnam, Sri Lanka, the United Arab Emirates, Malaysia and Japan. The items of the questions were content validated by content experts. Translation into target languages was carried out by standard forward-backward translation by native speakers. The translated questionnaire was also validated by new independent bilingual native speakers. The English and translated versions of the questionnaire were pilot tested in the respective countries before administration.

To ensure valid and reliable responses, we carried out survey data cleaning before analyses. Straightlining and duplicate responses were removed.

\section{Statistical analysis}

Descriptive statistics were calculated for the sample demographic characteristics, COVID-19 vaccine acceptance, vaccine characteristics influencing vaccination acceptance and desirable vaccine characteristics influencing the choice of vaccines. Subsequently, we analysed the distribution of the overall responses by regions and by individual countries.

Due to large sample size disparities between the participating countries, in statistical analysis of the pooled responses from all 17 countries, the data were adjusted based on sample weight in order to reflect the population size of respective countries. Population size weights were employed in the analyses to ensure that each country is represented in proportion to its population size [18]. The population size weight is calculated as PWEIGHT $=$ [Population size aged 15 years and above]/ [(Study sample size in country) $\times 10$ 000]. The country population size and the study sample size for all countries used in the weightage are shown in Additional file 2.

Multivariable logistic regression analysis was used to determine the factors associated with COVID-19 vaccine hesitancy $(1=$ extremely unlikely/unlikely; $0=$ likely/ extremely likely to receive the COVID-19 vaccine) and vaccine characteristics influencing vaccination acceptance. Crude and population size weighted odds ratio (OR) with $95 \% C I$ was computed to determine the level of significance. Hosmer-Lemeshow goodness-of-fit tests were used to ensure that the models adequately fit the data. Statistical significance was established at a $p$ value $<0.05$. All analyses were also conducted using SPSS version 22.0 (SPSS Inc., Chicago, IL, USA). 


\section{Ethical considerations}

The principal investigator obtained ethical approval in conducting the survey in a global context from the University of Malaya Research Ethics Committee (UM. TNC2/UMREC-1182). Additional ethical approvals were also sought from the Institutional Review Board of Mehran University of Engineering and Technology (MUET. IRB-04/01-2021), Indiana University Human Research Protection Program (Protocol \#: 10389) and Fujian Medical University, China (FJMU 2021 NO.63).

\section{Results}

In total, 19,714 responses from 17 countries were received. The sample size of the participatory countries ranges from 776 (Sri Lanka) to 2175 (Malaysia). The demographics of the overall participants, the region of origin, and the descriptive responses to the survey questions on COVID-19 vaccination intention, vaccine characteristics influencing acceptance, and first and second choice of vaccine characteristics influencing a COVID-19 vaccine choice are listed in Table 1 . Based on the results of analyses weighted by population, $53.8 \%$ of the study participants were female. Almost two-thirds of the participants (65.7\%) had a university degree, and most were aged 18-49 years old (80.1\%). The highest weighted prevalence of participation was from the Western Pacific (44.8\%) and Southeast Asia (36.4\%). Among the overall participants, $18.0 \%$ reported that they have ever delayed acceptance or refused any vaccine despite the availability of vaccination services in their countries. The demographics and descriptive responses to the survey questions by WHO regional category and individual 17 countries are detailed in Additional files 3 and 4, respectively.

\section{COVID-19 vaccination intention}

The majority of the study participants reported that they were likely (43.2\%) and extremely likely (47.2\%) to get vaccinated against COVID-19 (Table 1). Figure 1 shows the COVID-19 vaccination intention in the 17 countries. A high proportion of likely or extremely likely to receive the COVID-19 vaccine was reported in Australia (96.4\%), China (95.3\%) and Norway (95.3\%), while a high proportion reported being unlikely or extremely unlikely to receive the COVID-19 vaccine in Japan (34.6\%), the U.S. (29.4\%) and Iran (27.9\%). The highest proportion stating that they were extremely unlikely to receive the COVID19 vaccine was recorded in the U.S. (15.4\%). Figure 2 shows the distribution of COVID-19 vaccination intentions by WHO region. Southeast Asia and European regions reported high COVID-19 acceptance, whereas lower acceptance was reported in the Americas and Eastern Mediterranean regions.
Table 2 shows the multivariable logistic findings of factors influencing COVID-19 vaccine hesitancy for overall participants. Participants who ever delay or refuse vaccination ( ${ }_{\text {weighted }} O R=3.14 ; 95 \%$ CI 2.65-3.72), and those with the highest educational level of secondary school or below $(O R=1.91 ; 95 \%$ CI $1.51-2.42)$ presented higher odds of vaccine hesitancy. There was a gradual increase in the odds of COVID-19 vaccine hesitancy with age. Female reported lower vaccine hesitancy than males ( ${ }_{\text {weighted }} O R=0.84 ; 95 \%$ CI 0.72-0.98).

By WHO regional comparison (Additional file 5), higher vaccine hesitancy was reported with increasing age, except in the African region. Males expressed higher COVID-19 vaccine hesitancy in the region of the Americas $(O R=1.67 ; 95 \% C I 1.23-2.28)$ and Southeast Asia $(O R=1.55 ; 95 \% C I 1.16-2.07)$. In contrast, females expressed higher COVID-19 vaccine hesitancy $(O R=1.30 ; 95 \%$ CI 1.13-1.50) than males in the Western Pacific region. The multivariable logistic findings of factors influencing COVID-19 vaccine hesitancy for all 17 countries are shown in Additional file 6.

\section{Vaccine characteristics influencing vaccination acceptance} Findings on attitudes towards the vaccine characteristics revealed that $62.4 \%$ (95\% CI 61.2-63.6) do not mind if the COVID-19 vaccination needs more than one dose (Table 1). A total of 59.7\% (95\% CI 58.4-61.0) reported only accepting a vaccine with more than $90 \%$ effectiveness and $74.5 \%$ (95\% CI 73.4-75.5) would accept a COVID-19 vaccine with minor adverse reactions. Slightly over half (53.3\%; 95\% CI 52.0-54.6) reported only accepting a COVID-19 vaccine with a duration of protection of no less than 12 months. The majority of participants do not know about mRNA vaccines (45.1\%; 95\% CI 43.8-46.3) and 21.0\% (95\% CI 20.0-22.0) reported not accepting an mRNA vaccine. Slightly over half $(51.8 \%$; 95\% CI 50.5-53.1) reported that they would only accept a COVID-19 vaccine from a specific country-of-origin. Table 3 shows the vaccine characteristics influencing vaccination acceptance by demographics of all participants. Of particular note, participants with the highest level of education of secondary school and below were more likely to accept only single-dose vaccine, an effectiveness threshold no less than $90 \%$, and a vaccine with only minor adverse reactions. Participants of youngest age group (18-29 years) are more likely to not accept mRNA vaccines than the older age groups.

The distribution of attitudes about the vaccine characteristics by individual countries is shown in Fig. 3. Australia ranked highest in perceived acceptance of a single-dose COVID-19 vaccine, a duration of protection of not less than 12 months and only accepting a vaccine 
Table 1 Description of overall study participants' demographics, COVID-19 vaccination intention, and vaccine characteristics influencing vaccination acceptance and vaccine choice

\begin{tabular}{|c|c|c|}
\hline & $\begin{array}{l}\text { Participants } \\
n=19,714 \\
n(\%)\end{array}$ & $\begin{array}{l}\text { Weighted prevalence } \\
\%(95 C l)\end{array}$ \\
\hline \multicolumn{3}{|l|}{ Socio demography } \\
\hline \multicolumn{3}{|l|}{ Age group, years } \\
\hline $18-29$ & $5233(26.5)$ & $38.4(37.1-39.6)$ \\
\hline $30-39$ & $5524(28.0)$ & $25.4(24.3-26.6)$ \\
\hline $40-49$ & $4070(20.6)$ & $16.3(15.4-17.2)$ \\
\hline $50-59$ & $2751(14.0)$ & $12.0(11.2-12.9)$ \\
\hline 60 and above & $2136(10.8)$ & $7.9(7.3-8.5)$ \\
\hline \multicolumn{3}{|l|}{ Gender } \\
\hline Male & $9145(46.4)$ & $46.1(44.8-47.4)$ \\
\hline Female & $10,557(53.6)$ & $53.8(52.5-55.1)$ \\
\hline Other & $12(0.1)$ & $0.1(0.1-0.2)$ \\
\hline \multicolumn{3}{|l|}{ Highest education level } \\
\hline Secondary school and below & $2630(13.3)$ & $12.0(11.2-12.9)$ \\
\hline Certificate/A-Level/Diploma & $4856(24.6)$ & $22.3(21.2-23.4)$ \\
\hline Bachelor degree & $7883(40.0)$ & $42.5(41.2-43.8)$ \\
\hline Postgraduate degree & $4345(22.0)$ & $23.2(22.2-24.4)$ \\
\hline \multicolumn{3}{|l|}{ WHO region ${ }^{a}$} \\
\hline African & $1086(5.5)$ & $1.3(1.3-1.3)$ \\
\hline Eastern Mediterranean & $4122(20.9)$ & $7.1(7.1-7.1)$ \\
\hline European & $2403(12.2)$ & $1.9(1.9-1.9)$ \\
\hline Region of the Americas & $968(4.9)$ & $8.5(8.5-8.5)$ \\
\hline South-east Asia & $3436(17.4)$ & $36.4(36.4-36.4)$ \\
\hline Western Pacific & $7699(39.1)$ & $44.8(44.8-44.8)$ \\
\hline \multicolumn{3}{|c|}{ Ever delayed acceptance or refuse vaccine despite availability of vaccine service } \\
\hline Yes & $3812(19.3)$ & $18.0(17.1-19)$ \\
\hline No & $15,902(80.7)$ & $82.0(81-82.9)$ \\
\hline \multicolumn{3}{|l|}{ COVID-19 vaccine acceptance } \\
\hline Extremely likely & $8395(42.6)$ & $47.2(45.9-48.4)$ \\
\hline Likely & $8800(44.6)$ & $43.2(41.9-44.5)$ \\
\hline Unlikely & $1933(9.8)$ & $6.9(6.3-7.4)$ \\
\hline Extremely unlikely & $586(3.0)$ & $2.8(2.5-3.1)$ \\
\hline \multicolumn{3}{|c|}{ Vaccine characteristics influencing vaccination acceptance } \\
\hline \multicolumn{3}{|l|}{ Required doses of COVID-19 vaccine } \\
\hline Only accept single dose & $8025(40.7)$ & $37.6(36.4-38.8)$ \\
\hline Do not mind & $11,689(59.3)$ & $62.4(61.2-63.6)$ \\
\hline \multicolumn{3}{|l|}{ Effectiveness threshold of COVID-19 vaccine } \\
\hline Only accept 90\% threshold & $12,625(64.0)$ & $59.7(58.4-61.0)$ \\
\hline Do not mind & $7089(36.0)$ & $40.3(39.0-41.6)$ \\
\hline \multicolumn{3}{|l|}{ Adverse reactions of COVID-19 vaccine } \\
\hline Only accept minor adverse reactions & $14,002(71.0)$ & $74.5(73.4-75.5)$ \\
\hline Do not mind moderate adverse reactions & $5712(29.0)$ & $25.5(24.5-26.6)$ \\
\hline \multicolumn{3}{|l|}{ Duration of COVID-19 vaccine protection } \\
\hline Only accept no lesser than 12 months & $11,452(58.1)$ & $53.3(52.0-54.6)$ \\
\hline Do not mind & $8262(41.9)$ & $46.7(45.4-48.0)$ \\
\hline \multicolumn{3}{|l|}{ Technology used in COVID-19 vaccine } \\
\hline Do not accept mRNA technology & $4030(20.4)$ & $21.0(20.0-22.0)$ \\
\hline Do not mind & $6144(31.2)$ & $34.0(32.7-35.2)$ \\
\hline
\end{tabular}


Table 1 (continued)

\begin{tabular}{|c|c|c|}
\hline & $\begin{array}{l}\text { Participants } \\
n=19,714 \\
n(\%)\end{array}$ & $\begin{array}{l}\text { Weighted prevalence } \\
\%(95 \mathrm{Cl})\end{array}$ \\
\hline Do not know much about mRNA technology & $9540(48.4)$ & $45.1(43.8-46.3)$ \\
\hline \multicolumn{3}{|l|}{ Producing country of COVID-19 vaccine } \\
\hline Only accept a vaccine that is produced by specific countries & $11,919(60.5)$ & $51.8(50.5-53.1)$ \\
\hline Producing countries of a COVID-19 vaccine is not of my concern in vaccine acceptance & $7795(39.5)$ & $48.2(46.9-49.5)$ \\
\hline \multicolumn{3}{|l|}{ First foremost important vaccine characteristics influencing COVID-19 vaccine choice } \\
\hline Effectiveness threshold & $7719(39.2)$ & $35.1(30.1-40.5)$ \\
\hline Adverse reactions & $6387(32.4)$ & $40.6(33.2-48.4)$ \\
\hline Duration of protection & $1748(8.9)$ & $8.7(7.5-9.9)$ \\
\hline Administration doses & $1423(7.2)$ & $7.2(5.1-10.2)$ \\
\hline Country of origin & $907(4.6)$ & $3.4(1.9-5.8)$ \\
\hline Vaccination cost & $861(4.4)$ & $2.5(1.0-6.1)$ \\
\hline mRNA technology & $639(3.2)$ & $2.5(1.7-3.7)$ \\
\hline \multicolumn{3}{|l|}{ Second important vaccine characteristics influencing COVID-19 vaccine choice } \\
\hline Adverse reactions & $5140(26.1)$ & $24.2(17.8-31.9)$ \\
\hline Duration of protection & $4630(23.5)$ & $29.0(24.8-33.5)$ \\
\hline Effectiveness threshold & $3729(18.9)$ & $22.5(18.3-27.4)$ \\
\hline Country or origin & $2907(14.7)$ & $9.3(4.5-17.9)$ \\
\hline Cost of vaccination & $1428(7.2)$ & $4.1(1.7-9.6)$ \\
\hline Administration doses & $1230(6.2)$ & $7.1(6.0-8.3)$ \\
\hline mRNA technology & $589(3.0)$ & $3.9(3.3-4.6)$ \\
\hline
\end{tabular}

a African: South Africa; Eastern Mediterranean: Iran, Pakistan, Somalia, United Arab Emirates; European: Norway, United Kingdom; Region of the Americas: United States of America; South-East Asia: Bangladesh, India, Sri Lanka; Western Pacific: Australia. China, Japan, Malaysia, Singapore, Vietnam

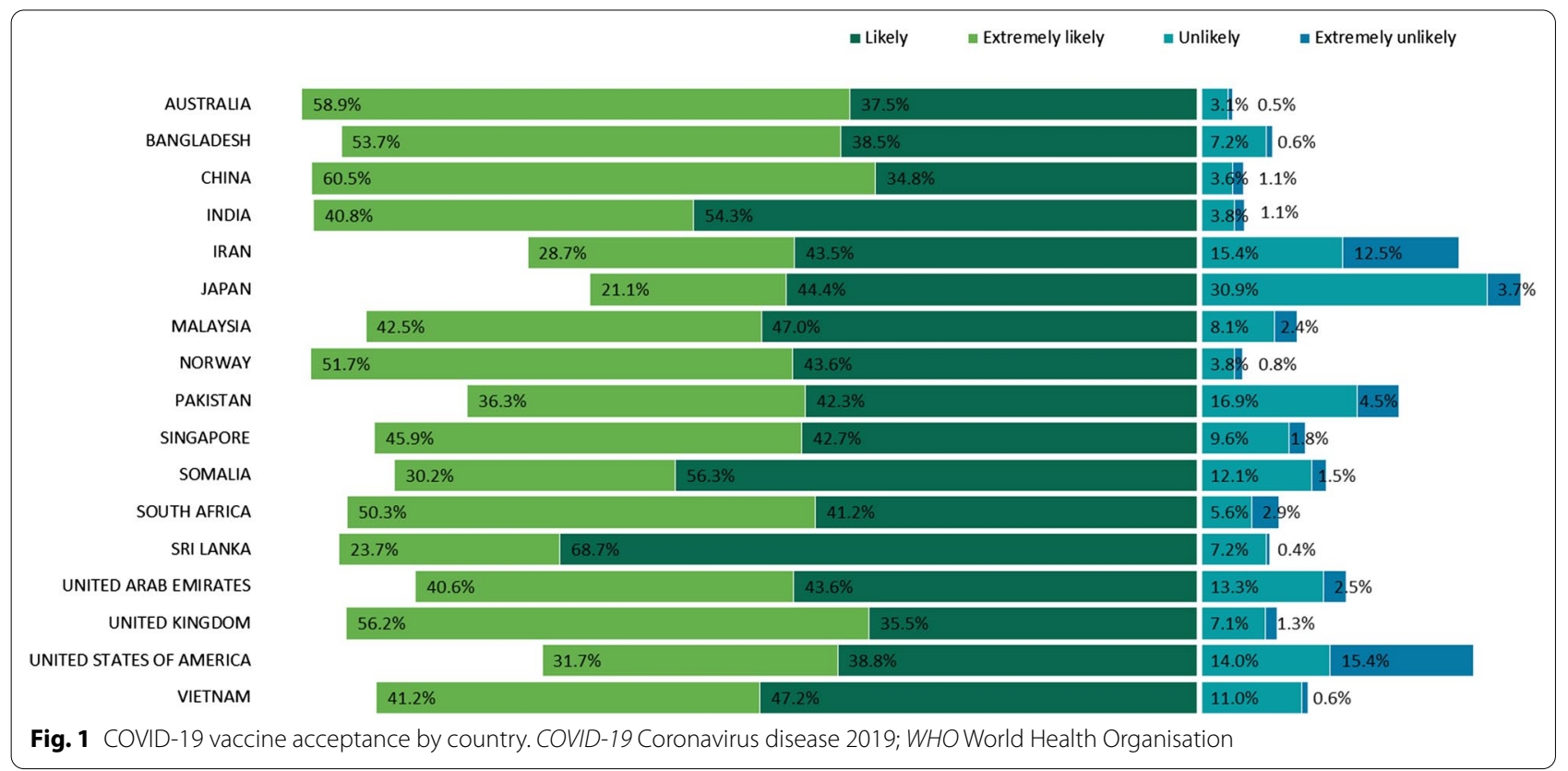

produced by certain countries. Somalia (48.4\%) and Sri Lanka (46.1\%) recorded the highest proportion that would not accept an mRNA vaccine. Japan (72.2\%) and
Iran (71.4\%) recorded a higher proportion that do not know about mRNA vaccines. Figure 4 shows the distribution of attitudes about the vaccine characteristics by 


\begin{tabular}{|c|c|c|c|c|c|c|}
\hline & & & — Likely & Extremely likely & = Unlikely & - Extremely unlikely \\
\hline AFRICAN & $50.3 \%$ & & & & & \\
\hline AMERICAS & & $31.7 \%$ & & & & $15.4 \%$ \\
\hline EASTERN MEDITERRANEAN & & $34.1 \%$ & & & & $5.3 \%$ \\
\hline EUROPEAN & $53.6 \%$ & & & & & \\
\hline SOUTHEAST ASIA & $41.0 \%$ & & $52.5 \%$ & & & \\
\hline WESTERN PACIFIC & $44.7 \%$ & & & & & $7 \%$ \\
\hline
\end{tabular}

Table 2 Demographic characteristics influencing COVID-19 vaccination hesitancy

\begin{tabular}{|c|c|c|c|}
\hline & \multirow[t]{2}{*}{ Participants $(n=19714)$} & \multicolumn{2}{|c|}{$\begin{array}{l}\text { Extremely unlikely/unlikely vs extremely likely/likely to accept } \\
\text { COVID-19 vaccination }(n=2518)\end{array}$} \\
\hline & & Unweighted OR $(95 \% \mathrm{Cl})$ & Weighted OR $(95 \% \mathrm{Cl})$ \\
\hline \multicolumn{4}{|l|}{ Socio demography } \\
\hline \multicolumn{4}{|l|}{ Age group, years } \\
\hline $18-29$ & $5233(26.5)$ & 1 (reference) & 1 (reference) \\
\hline $30-39$ & $5524(28.0)$ & $1.22(1.08-1.38)^{* * *}$ & $1.43(1.14-1.79)^{* *}$ \\
\hline $40-49$ & $4070(20.6)$ & $1.31(1.14-1.49)^{* * *}$ & $1.89(1.48-2.4)^{* * *}$ \\
\hline $50-59$ & $2751(14.0)$ & $1.61(1.40-1.86)^{* *}$ & $1.86(1.445-2.40)^{* * *}$ \\
\hline 60 and above & $2136(10.8)$ & $2.30(2.00-2.66)^{* * *}$ & $3.64(2.84-4.65)^{* * *}$ \\
\hline \multicolumn{4}{|l|}{ Gender } \\
\hline Male & $9145(46.4)$ & 1 (reference) & 1 (reference) \\
\hline Female & $10,557(53.6)$ & $1.03(0.95-1.13)$ & $0.84(0.72-0.98)^{*}$ \\
\hline Other & $12(0.1)$ & - & - \\
\hline \multicolumn{4}{|l|}{ Highest education level } \\
\hline Secondary school and below & $2630(13.3)$ & $2.19(1.91-2.51)^{* * *}$ & $1.91(1.51-2.42)^{* * *}$ \\
\hline Certificate/A-Level/Diploma & $4856(24.6)$ & $1.04(0.91-1.18)$ & $0.91(0.72-1.16)$ \\
\hline Bachelor degree & $7883(40.0)$ & $1.09(0.97-1.23)$ & $1.02(0.83-1.27)$ \\
\hline Postgraduate degree & $4345(22.0)$ & 1 (reference) & 1 (reference) \\
\hline \multicolumn{4}{|c|}{ Ever delayed acceptance or refuse vaccine despite availability of vaccine service } \\
\hline Yes & $3812(19.3)$ & $2.60(2.37-2.85)^{* * *}$ & $3.14(2.65-3.72)^{* * *}$ \\
\hline No & $15,902(80.7)$ & 1 (reference) & 1 (reference) \\
\hline
\end{tabular}

Hosmer-Lemeshow goodness-of-fit Chi-square $=16.834, P$-value $=0.032$; Unweighted Nagelkerke $R^{2}=0.075$; Weighted Nagelkerke $R^{2}=0.091$ ${ }^{*} P<0.05,{ }^{* *} P<<0.01, * * * P<<0.001$

WHO region. Countries from the Southeast Asia region reported the highest proportion not accepting mRNA technology, and only accepting minor adverse reactions and a single-dose vaccine. The highest proportion of the European and Americas regions reported only accepting a vaccine produced by certain countries. The multivariable logistic findings of demographic factors influencing COVID-19 vaccine characteristic acceptance for the 17 individual countries are shown in Additional file 7 
Table 3 Vaccine characteristics influencing vaccination acceptance by demographics $(N=19,702)$

\begin{tabular}{|c|c|c|c|c|c|c|}
\hline & $\begin{array}{l}\text { Required doses } \\
\text { of COVID-19 } \\
\text { vaccine }^{a}\end{array}$ & $\begin{array}{l}\text { Effectiveness } \\
\text { threshold of } \\
\text { COVID-19 } \\
\text { vaccine }^{\text {b }}\end{array}$ & $\begin{array}{l}\text { Adverse reactions } \\
\text { of COVID-19 } \\
\text { vaccine }^{c}\end{array}$ & $\begin{array}{l}\text { Duration of } \\
\text { COVID-19 vaccine } \\
\text { protection }^{d}\end{array}$ & $\begin{array}{l}\text { Technology used } \\
\text { in COVID-19 } \\
\text { vaccine }^{\text {e }}\end{array}$ & $\begin{array}{l}\text { Producing country } \\
\text { of COVID-19 } \\
\text { vaccine }^{f}\end{array}$ \\
\hline & $\begin{array}{l}\text { Weighted } \\
\text { OR }(95 \% \mathrm{Cl})\end{array}$ & $\begin{array}{l}\text { Weighted } \\
\text { OR }(95 \% \mathrm{Cl})\end{array}$ & $\begin{array}{l}\text { Weighted } \\
\text { OR }(95 \% \mathrm{Cl})\end{array}$ & $\begin{array}{l}\text { Weighted } \\
\text { OR }(95 \% \mathrm{Cl})\end{array}$ & $\begin{array}{l}\text { Weighted } \\
\text { OR }(95 \% \mathrm{Cl})\end{array}$ & $\begin{array}{l}\text { Weighted } \\
\text { OR }(95 \% \mathrm{Cl})\end{array}$ \\
\hline \multicolumn{7}{|l|}{ Socio demography } \\
\hline \multicolumn{7}{|l|}{ Age group, years } \\
\hline $18-29$ & 1 (reference) & 1 (reference) & 1 (reference) & 1 (reference) & 1 (reference) & 1 (reference) \\
\hline $30-39$ & $1.63(1.41-1.87)^{* * * *}$ & $0.72(0.63-0.83)^{* * *}$ & $0.58(0.49-0.68)^{* * *}$ & $1.01(0.88-1.16)$ & $1.60(1.03-2.47)$ & $0.99(0.85-1.14)$ \\
\hline $40-49$ & $1.89(1.61-2.22)^{* * *}$ & $0.53(0.45-0.62)^{* * *}$ & $0.45(0.38-0.54)^{* * *}$ & $0.99(0.85-1.16)$ & $2.29(1.4-3.75)^{* * *}$ & $0.91(0.78-1.06)$ \\
\hline $50-59$ & $1.91(1.59-2.28)^{* * *}$ & $0.61(0.51-0.73)^{* * *}$ & $0.41(0.34-0.51)^{* * *}$ & $0.98(0.82-1.17)$ & $2.55(1.52-4.29)^{* * *}$ & $0.81(0.75-1.06)$ \\
\hline 60 and above & $1.14(0.93-1.387)$ & $0.69(0.56-0.84)^{* * *}$ & $0.41(0.33-0.51)^{* * *}$ & $1.01(0.84-1.22)$ & $1.26(0.71-2.26)^{*}$ & $0.84(0.69-1.02)$ \\
\hline \multicolumn{7}{|l|}{ Gender } \\
\hline Male & 1 (reference) & 1 (reference) & 1 (reference) & 1 (reference) & 1 (reference) & 1 (reference) \\
\hline Female & $0.86(0.78-0.96)^{* *}$ & $1.12(1.01-1.25)^{*}$ & $1.09(0.97-1.23)$ & $1.07(0.96-1.19)$ & $1.31(1.08-1.57)^{* * *}$ & $1.08(0.97-1.21)$ \\
\hline \multicolumn{7}{|c|}{ Highest education level } \\
\hline $\begin{array}{l}\text { Secondary school } \\
\text { and below }\end{array}$ & $1.54(1.27-1.85)^{* *}$ & $1.37(1.12-1.68)^{* * *}$ & $1.04(0.83-1.31)$ & $1.33(1.10-1.61)^{* * *}$ & $0.79(0.45-1.38)$ & $1.08(0.90-1.30)$ \\
\hline $\begin{array}{l}\text { Certificate/A- } \\
\text { Level/Diploma }\end{array}$ & $1.42(1.21-1.66)^{* * *}$ & $0.78(0.66-0.91)^{* * *}$ & $0.58(0.49-0.69)^{* * *}$ & $0.91(0.77-1.06)$ & $1.00(0.64-1.59)$ & $1.04(0.89-1.21)$ \\
\hline Bachelor degree & $1.20(1.04-1.38)^{* * * *}$ & $0.99(0.86-1.15)$ & $0.86(0.73-1.01)$ & $1.04(0.91-1.20)$ & $0.78(0.49-1.25)$ & $0.84(0.73-0.97)^{*}$ \\
\hline $\begin{array}{l}\text { Postgraduate } \\
\text { degree }\end{array}$ & 1 (reference) & 1 (reference) & 1 (reference) & 1 (reference) & 1 (reference) & 1 (reference) \\
\hline \multicolumn{7}{|c|}{ Ever delayed acceptance or refuse vaccine despite availability of vaccine service } \\
\hline Yes & $1.71(1.49-1.96)^{* * *}$ & $1.77(1.52-2.07)^{* * *}$ & $1.82(1.52-2.16)^{* * *}$ & $1.52(1.32-1.75)^{* * *}$ & $1.284(0.783-2.107)$ & $0.63(0.55-0.73)^{* * *}$ \\
\hline No & 1 (reference) & 1 (reference) & 1 (reference) & 1 (reference) & 1 (reference) & 1 (reference) \\
\hline
\end{tabular}

Other gender was excluded due to small sample size

a: Only accept single dose vs Do not mind, b: Only accept $90 \%$ threshold vs Do not mind, c: Only accept minor adverse reactions vs Do not mind moderate adverse reactions, $\mathrm{d}$ : Only accept lesser than 12 months vs Do not mind moderate adverse reactions, e: Do not accept mRNA technology vs Do not know much about mRNA technology/Do not mind, f: Only accept a vaccine that is produced by specific countries vs Producing countries of a COVID-19 vaccine is not of my concern in vaccine choice

a $P$-value: $P<0.001$; Nagelkerke $R^{2}: 0.044$

b $P$-value: $P<0.001$; Nagelkerke $R^{2}: 0.044$

c $P$-value: 0.001; Nagelkerke $R^{2}: 0.066$

d $P$-value: 0.001; Nagelkerke $R^{2}: 0.013$

e $P$-value: 0.001 ; Nagelkerke $R^{2}: 0.013$

f $P$-value: 0.010; Nagelkerke $R^{2}: 0.014$

${ }^{*} P<0.05$, ${ }^{* *} P<<0.01,{ }^{* * *} P<<0.001$

\section{Desirable vaccine characteristics influencing vaccine choice}

The foremost important vaccine characteristic influencing vaccine choice is adverse reactionss $(40.6 \%$; $95 \%$ CI 39.3-41.9) of a vaccine and effectiveness threshold (35.1\%; 95\% CI 33.9-36.4). The second most important factors were the duration of protection $(29.0 \%$; $95 \%$ CI $27.8-30.2)$ and adverse reactions of a vaccine $(24.2 \%$; $95 \%$ CI 23.0-25.4). The first and second most important vaccine characteristics influencing vaccine choice of the 17 individual countries are shown in Additional file 4

\section{Discussion}

The survey assessed COVID-19 vaccination acceptance among 19,714 respondents from 17 countries across all WHO regions as soon as the United States Food and Drug Administration (FDA) authorised vaccines and their roll-out started around the world. The finding of $90.4 \%$ reporting being likely or extremely likely to accept vaccination implies a high level of COVID-19 vaccine intention. Vaccine intention varies from the highest of $96.4 \%$ (Australia) to the lowest of $65.5 \%$ (Japan). By region, the countries in Southeast Asia reported the 

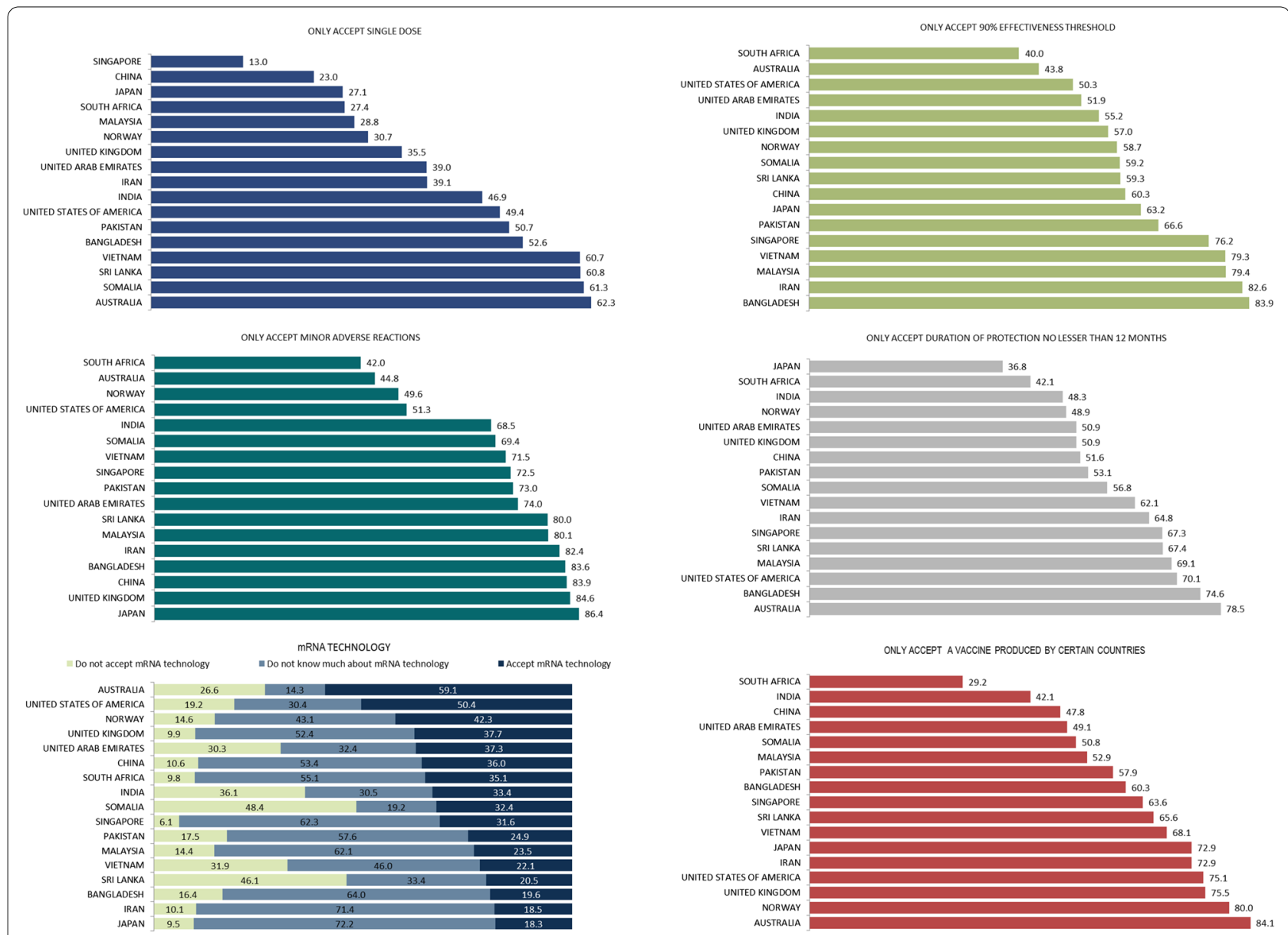

Fig. 3 COVID-19 vaccine characteristics preferences by country. COVID-19 Coronavirus disease 2019, WHO World Health Organisation

highest acceptance and the Americas reported the lowest. As with a previous global study of COVID-19 vaccination intention [19], acceptance tended to be high in the Asian nations, where the public has strong institutional trust. A notable exception is Japan, a country known to have one of the lowest rates of vaccine confidence worldwide [20] and this was similar to the results found for COVID-19 vaccine intent in our study. A recent study of COVID-19 vaccination intention among Japanese people similarly found a vaccination intention of only 65.7\% [21]. Our findings echo the relatively low intentions for COVID-19 vaccination among people in the U.S. [22-25]. Based on estimates that vaccination coverage of approximately $75 \%$ may be required to control the current epidemic [26], the current findings suggest that Iran, the U.S. and Japan (the countries with vaccination intention below the threshold) would warrant concerted efforts to improve acceptability and uptake in their populations.

In this study, hesitancy was almost two-fold higher among people aged 60 years and older than other younger age groups. Reports of deaths occurring in the elderly who received a COVID-19 vaccine made headlines worldwide [27, 28], perhaps raising some concern about the vaccines that are too risky for the elderly, resulting in an increase in hesitancy among the elderly. As COVID-19 vaccination is underway in many countries, and people aged 65 and older are the initial priority group for a COVID-19 vaccination program in many countries, providing information and support to older people is important to enhance vaccination coverage in older adults. On the whole, the prevalence of COVID19 vaccine hesitancy remains disproportionately high in individuals who have an education level of secondary level and below, which is a consistent finding across regions and many individual countries. Higher level of COVID-19 vaccine hesitancy in people with lower education levels found in this study can be explained by preexisting vaccine hesitancy in these groups, namely due to lower knowledge about vaccines and health literacy; in addition, lower trust in healthcare professionals, the health system and the government [29, 30]. Research shows that better educated individuals are more likely 

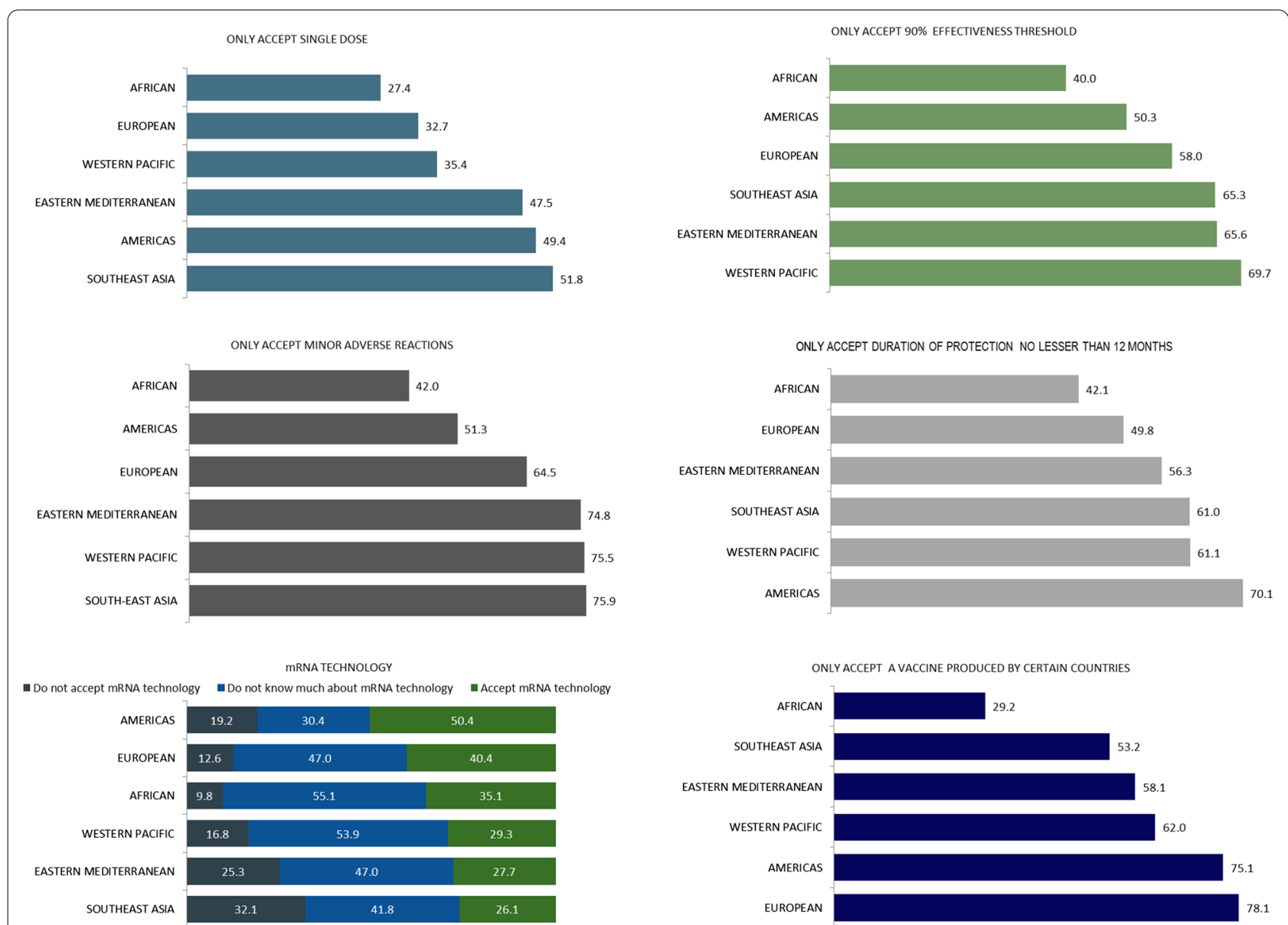

Fig. 4 COVID-19 vaccine characteristics preferences by WHO region. COVID-19 Coronavirus disease 2019, WHO World Health Organisation

to understand public health messages and access reliable information on the safety and effectiveness of vaccines [31]. The findings bring to light the importance of developing targeted interventions within each country, directed at subgroups who are hesitant, to increase vaccination confidence and coverage.

This study shows that vaccine characteristics have an important influence on the participants' vaccination acceptance. As the highest proportion reported only accepting a COVID-19 vaccine with minor adverse reactions, this indicates that the safety of a new COVID-19 vaccine is an extremely important characteristic for vaccine acceptance. It is possible that people worldwide are worried about the safety of vaccines because of their novelty and the fact that the COVID-19 vaccine is also the first in history being approved for emergency use and rolled out on a global scale. The public should be made known that despite being rolled out for emergency use, the COVID-19 vaccines have gone through rigorous, multi-stage testing processes, including large clinical trials, and were found to be safe and effective [32]. The recent evidence of reductions of SARS-CoV-2 infections, hospitalisations and deaths following nationwide COVID-19 vaccinations should also be informed to the public [33, 34].

Of notable importance, this study found a high proportion indicating that they would only accept vaccines with a threshold of above $90 \%$ effectiveness. There has been a widespread comparison of the efficacy rates of the COVID-19 vaccines in the news media [35, 36]. This might lead people to be more unwilling to accept vaccines with a lower level of effectiveness, having the impression that a lower level of effectiveness means that they are inferior. Nevertheless, the public should be informed that the effectiveness of these vaccines has not been compared directly, so comparative effectiveness remains largely unknown. Also, the most widely reported efficacy data is based on an endpoint of symptomatic disease, whereas there may be less variability across vaccines when considering severe disease or hospitalization as the endpoint. Given the uncertainty of the comparison of the effectiveness of the currently available COVID-19 
vaccines, the public should be informed that with high immunisation rates, a vaccine with an effectiveness of just $60 \%$ or $70 \%$ may be sufficient to reach herd immunity and potentially control the pandemic [26]. Hence, it is essential to educate members about herd immunity and the importance of concerted efforts to ensure successful vaccination of a large proportion of the population to achieve high immunisation coverage rates.

In this study, a substantially high proportion of people in the Europe and Americas regions reported not accepting a COVID-19 vaccine produced by specific countries. In contrast, Southeast Asia and African regions expressed less concern surrounding the country-of-origin of the COVID-19 vaccine. The disparities in COVID-19 vaccine acceptance found in this study has tremendously important implications for respective governments in the choice of vaccine to be introduced in their countries' vaccination implementation program. The general public should be made aware that all three of the COVID-19 vaccines currently authorised by the FDA as well as other COVID-19 vaccines that have received regulatory approval from the countries' origin regulatory approval have been proven to be safe and effective for their intended use. There is a need to increase the public's faith in any approved vaccine offered to them. Given the urgency in vaccine deployment and reaching high coverage, the public should be encouraged to accept the COVID-19 vaccines offered to them.

Our findings also indicate vaccine hesitancy increasing due to the uncertainty surrounding the duration of protection and the number of doses, making these of considerable concern. Unfortunately, the questions surrounding the duration of vaccine-elicited protection and the need for booster injections are currently the focus of ongoing investigations and it is unknown whether booster doses will be needed. Currently, 6 months after the authorization of the COVID-19 vaccines, real-world data from several countries has continued to demonstrate strong protection against SARS-CoV-2 infections through 6 months post-second dose [37, 38]. Despite preceding speculations that the mutations of SARSCoV-2 would adversely affect the efficacy of the COVID19 vaccines, to date, mounting evidence showed that the COVID-19 vaccines coffer protection against the current prevailing variants of the SARS-CoV-2. Earlier in the pandemic, evidence indicated that vaccines are unlikely to be affected by the 'D614G' mutation (aspartate-to-glycine change at position 614) of the SARSCoV-2 spike protein [39]. Preliminary laboratory studies on the mRNA vaccine reported that it offers protection from multiple variants including the B.1.351 variant first found in South Africa, the B.1.1.7 variant first found in the United Kingdom, and the P.1 variant first found in
Brazil [40, 41]. A recent serosurvey study showed that BNT162b2 vaccine-elicited antibodies efficiently neutralize SARS-CoV-2 authentic viruses belonging to B.1, B.1.1.7, B.1.351, B.1.525 and P.1 lineages [42]. It remains a challenge to convince the public to accept a new vaccine with unknown duration of protection. Nonetheless, highlighting these recent evidence-based facts will be useful to counteract the fear of being vaccinated with a vaccine that may no longer provide protection against COVID-19.

Our study found that a minority, particularly people from the Southeast Asia region, were concerned about getting vaccines developed using mRNA technology. The ground-breaking approach previously had not been tested in humans, causing concerns about possible safety issues [43]. It remains a challenge in introducing the new mRNA vaccines and clearly communicating that they have been adequately evaluated for safety and efficacy in clinical trials, despite the fact that they involve relatively new biotechnology $[44,45]$. The mRNA vaccines have been subjected to many conspiracy theories since they were launched [46]. The benefits of the mRNA vaccine along with the current safety evidence [44, 47-49] should be highlighted to demystify the unfounded conspiracy theories and criticism.

Currently, in many countries, the public may not have the option to choose the type of COVID-19 vaccine that they favour; however, the responses to factors influencing the choice of vaccine imply that, above all, the safety and efficacy of the new vaccines are of paramount importance to the world population. Thus, efforts need to be made to build trust in the safety and efficacy of the vaccines offered to the general population within all countries. Since there are still many uncertainties surrounding the risks of the new COVID-19 vaccines, media reports of COVID-19 vaccines causing serious or lethal side effects might cause public uproar and fear, resulting in people refusing vaccination. There is a strong need to educate the public and media outlets that anecdotal evidence is not a valid way to determine safety or efficacy.

A large population-based SARS-CoV-2 seroepidemiological study in Germany reported that about 20\% of individuals lost their neutralizing antibodies within 5 months post infection and neutralizing antibodies are detectable in only one-third of individuals who were tested positive [50]. A recent finding of the first long-term seroprevalence study in Wuhan, China after the lockdown lifted revealed that only around $7 \%$ of the population had COVID-19 antibodies, with approximately $40 \%$ of this population developing neutralising antibodies that potentially protect against future infection [51]. This evidence supports the need for mass vaccination to reach herd immunity and should 
be highlighted to all communities globally to prevent further resurgences of the pandemic. A whole-of-society approach is needed to achieve a successful global COVID-19 vaccine program.

The main limitation of this study was the use of the convenience sampling method to administer the questionnaire, which may have introduced selection bias and affected generalisation to the wider populations. Secondly, we recognise that this study has a strong representation of countries in the Southeast Asia, Eastern Mediterranean, and Western Pacific regions, but limited representation in the Americas, Africa, and European regions. Also noteworthy for the present study, the native language option of the survey questions was available for the survey conducted in China, Vietnam, Sri Lanka, the United Arab Emirates, Malaysia, and Japan, which may introduce a biased representation of English-speaking participants for countries where native language option was not available.

\section{Conclusions}

The refusal of COVID-19 vaccination could prolong the battle against this pandemic and result in needless suffering and death. The findings provide the demographic targets of the people who most need to be reached for respective countries and regions to increase vaccine acceptance and uptake rates. It is clear that the different types of COVID-19 vaccines with diverse characteristics that are currently available may increase uncertainty and difficulty in making a decision, resulting in people delaying or refusing vaccination. Furthermore, not being able to have the option to freely choose a favoured vaccine may heighten hesitancy. Given the importance of moving quickly to roll out the vaccine to reach a herd immunity threshold, and the current situation of insufficient supply to meet the current global demand, addressing this reluctance through evidence gained from this study would be advantageous. It is of paramount importance that all countries develop individually-tailored strategies to strengthen the confidence of their population in vaccination, irrespective of the types of COVID-19 vaccines offered in their national vaccination program. Our findings may also provide insights enabling public health messages to be tailored to enhance COVID-19 vaccine uptake efforts worldwide.

\footnotetext{
Abbreviations

Cl: Confidence interval; COVID-19: Coronavirus disease 2019; FDA: Food and Drug Administration; mRNA: Messenger RNA; OR: Odds ratio; SARS-CoV-2: Severe acute respiratory syndrome coronavirus 2; USA: United States of America; WHO: World Health Organisation.
}

\section{Supplementary Information}

The online version contains supplementary material available at https://doi. org/10.1186/s40249-021-00900-w.

Additional file 1. Questionnaire.

Additional file 2. The population size of age 15 years and the sample population by country.

Additional file 3. Participant demographics, vaccine characteristics influencing vaccination acceptance and vaccine characteristics influencing choice by region.

Additional file 4. Participant demographics, vaccine characteristics influencing vaccination acceptance and vaccine characteristics influencing choice by country.

Additional file 5. Factors influencing COVID-19 vaccine hesitancy by region.

Additional file 6. Factors influencing COVID-19 vaccine hesitancy by country.

Additional file 7. Vaccine characteristics influencing vaccination acceptance by demographics for individual country.

\section{Acknowledgements}

The author would like to thank all participants of the study for their participation in the investigation.

\section{Authors' contributions}

LPW, ZG, and QZ designed and conceptualized the study. JA, AL, CZC, YL, ZH, SYT, YL, GC, KND, NS, FA, MDM, MA, TQ, SM, GZ and QZ collected the data. LPW, $\mathrm{HA}$ and MD analysed the data. LPW wrote the whole manuscript. GZ and QZ reviewed the manuscript. All authors read and approved the final manuscript.

\section{Funding}

Data collection in China was supported by The Pilot Project of Fujian Provincial Department of Science \& Technology (No. 2020Y0005).

\section{Availability of data and materials}

All data generated or analysed during this study are included in this published article [and its additional information files].

\section{Declarations}

\section{Ethics approval and consent to participate}

This study was approved by the University of Malaya Research Ethics Committee (UM.TNC2/UMREC-1182), Institutional Review Board of Mehran University of Engineering and Technology (MUET.IRB-04/01-2021), Indiana University Human Research Protection Program (Protocol \#: 10389) and Fujian Medical University, China (FJMU 2021 NO.63).

\section{Consent for publication}

Not applicable.

\section{Competing interests}

Outside of the present work GDZ has served as an external advisory board member for Merck and Moderna and as a consultant to Merck. In addition, he has received investigator-initiated research funding from Merck administered through Indiana University.

\footnotetext{
Author details

${ }^{1}$ Department of Epidemiology and Health Statistics, Fujian Provincial Key Laboratory of Environment Factors and Cancer, School of Public Health, Fujian Medical University, Fuzhou 350122, Fujian, China. ${ }^{2}$ Centre for Epidemiology and Evidence-Based Practice, Department of Social and Preventive Medicine, Faculty of Medicine, University of Malaya, 50603 Kuala Lumpur, Malaysia.

${ }^{3}$ Department of Community Health Science, Muhammad Medical College,
} 
Mirpurkhas, Sindh 69000, Pakistan. ${ }^{4}$ World Health Organization National Polio Surveillance Project (NPSP) Unit Belgaum World Customs Organization, Hindu Nagar, Tilakwadi, Belgaum, Karnataka 590006, India. ${ }^{5}$ Leadership Institute for Global Health Transformation, Saw Swee Hock School of Public Health, National University of Singapore, 12 Science Drive, Singapore 117549, Singapore. ${ }^{6}$ Department of Public Health, Nagasaki University Graduate School of Biomedical Sciences, Nagasaki 852-8523, Japan. ${ }^{7}$ Department of Academic Affairs and Testing, Dong Nai Technology University, Dong Nai, Vietnam. ${ }^{8}$ Institute of Epidemiology, Disease Control \& Research (IEDCR), Mohakhali, Dhaka 1212, Bangladesh. ${ }^{9}$ Ministry of Health and Prevention (MOHAP), Sharjah, United Arab Emirates. ${ }^{10}$ Vijaya College of Nursing, Belgaum, Ayodhya Nagar, Belgaum, Karnataka 590001, India. ${ }^{11}$ Department of Nursing, Faculty of Allied Health Sciences, University of Peradeniya, Peradeniya, Sri Lanka. ${ }^{12}$ Leadership Dialogue, 16 Elland Road, Manor Gardens, Durban 4001, South Africa. ${ }^{13}$ Nursing and Midwifery Care Research Center, Mashhad University of Medical Sciences, Mashhad, Iran. ${ }^{14}$ Department of Pediatrics, School of Medicine, Indiana University, 410 W, 10th St., HS 1001, Indianapolis, IN 46202, USA. ${ }^{15}$ State Key Laboratory of Molecular Vaccinology and Molecular Diagnostics, National Institute of Diagnostics and Vaccine Development in Infectious Diseases, School of Public Health, Xiamen University, Xiamen, Fujian, China.

Received: 14 June 2021 Accepted: 30 August 2021

Published online: 07 October 2021

\section{References}

1. WHO. Archived:WHO timeline-COVID-19. 27 April 2020. 2020. https:// www.who.int/news/item/27-04-2020-who-timeline---covid-19. Accessed 23 Aug 2021.

2. $\mathrm{WHO}, \mathrm{WHO}$ Director-General's opening remarks at the media briefing on COVID-19-11 March 2020. 2020. https://www.who.int/dg/speeches/ detail/who-director-general-s-opening-remarks-at-the-media-briefingon-covid-19---11-march-2020. Accessed 23 Aug 2021.

3. UNHCR Malaysia. Public Health during COVID-19. https://www.unhcr.org/ en-my/health-covid-19.html. Accessed 23 Aug 2021.

4. WHO. Weekly epidemiological update-2 March 2021. 2021. https:// www.who.int/publications/m/item/weekly-epidemiological-update---2march-2021. Accessed 5 Mar 2021.

5. WHO. Draft landscape and tracker of COVID-19 candidate vaccines. 2021. https://www.who.int/publications/m/item/draft-landscape-of-covid-19candidate-vaccines. Accessed 31 Mar 2021.

6. WHO. Ten threats to global health in 2019. 2019. https://www.who.int/ vietnam/news/feature-stories/detail/ten-threats-to-global-health-in2019. Accessed 31 Mar 2021

7. Abdool Karim SS, de Oliveira T. New SARS-CoV-2 variants_clinical, public health, and vaccine implications. N Engl J Med. 2021. https://doi.org/10. 1056/NEJMc2100362.

8. Kim JH, Marks F, Clemens JD. Looking beyond COVID-19 vaccine phase 3 trials. Nat Med. 2021;27:205-11. https://doi.org/10.1038/ s41591-021-01230-y.

9. Schwarzinger M, Watson V, Arwidson P, Alla F, Luchini S. COVID-19 vaccine hesitancy in a representative working-age population in France: a survey experiment based on vaccine characteristics. Lancet Public Health. 2021;6:e210-21. https://doi.org/10.1016/S2468-2667(21)00012-8.

10. Callaway E. Russia's fast-track coronavirus vaccine draws outrage over safety. Nature. 2020;584:334-5. https://doi.org/10.1038/ d41586-020-02386-2.

11. Lin C, Tu P, Beitsch LM. Confidence and receptivity for COVID-19 vaccines: a rapid systematic review. Vaccines. 2021;9:16. https://doi.org/10.3390/ vaccines9010016.

12. Kreps S, Prasad S, Brownstein JS, Hswen Y, Garibaldi BT, Zhang B, Kriner DL. Factors associated with US adults' likelihood of accepting COVID-19 vaccination. JAMA Netw Open. 2020;3:e2025594. https://doi.org/10.1001/ jamanetworkopen.2020.25594.

13. Iserson KV. SARS-CoV-2 (COVID-19) vaccine development and production: an ethical way forward. Camb Q Healthc Ethics. 2021;30:59-68. https://doi.org/10.1017/S096318012000047X.
14. Limaye RJ, Sauer M, Truelove SA. Politicizing public health: the powder keg of rushing COVID-19 vaccines. Hum Vaccine Immunother. 2021;17:1662-3. https://doi.org/10.1080/21645515.2020.1846400.

15. Ward JK, Alleaume C, Peretti-Watel P, Seror V, Cortaredona S, Launay O, et al. The French public's attitudes to a future COVID-19 vaccine: the politicization of a public health issue. Soc Sci Med. 2020;265:113414. https://doi.org/10.1016/j.socscimed.2020.113414.

16. Daniel WW, Cross CL. Biostatistics: a foundation for analysis in the health sciences. Hoboken: Wiley; 2018.

17. Wejnert C, Pham H, Krishna N, Le B, DiNenno E. Estimating design effect and calculating sample size for respondent-driven sampling studies of injection drug users in the United States. AIDS Behav. 2012;16:797-806. https://doi.org/10.1007/s10461-012-0147-8.

18. Fotini T, Evanlagia $\vee$, Michail $V$. Weighting of responses in the consumer survey: alternative approaches - effects on variance and tracking performance of the Consumer Confidence Indicator. November 2013. 2013. https://www.oecd.org/sdd/leading-indicators/IOBE\%20M.Vassileiadis_ Weighting\%20of\%20responses\%20in\%20the\%20Consumer\%20Survey-\% 20Effects\%20on\%20the\%20Consumer\%20Confidence\%20lndicator_ paper.pdf. Accessed 6 Apr 2021

19. Lazarus JV, Ratzan SC, Palayew A, Gostin LO, Larson HJ, Rabin K, et al. A global survey of potential acceptance of a COVID-19 vaccine. Nat Med. 2021;27:225-8. https://doi.org/10.1038/s41591-020-1124-9.

20. De Figueiredo A, Simas C, Karafillakis E, Paterson P, Larson HJ. Mapping global trends in vaccine confidence and investigating barriers to vaccine uptake: a large-scale retrospective temporal modelling study. Lancet. 2020;396:898-908. https://doi.org/10.1016/S0140-6736(20)31558-0.

21. Yoda T, Katsuyama $\mathrm{H}$. Willingness to receive COVID-19 vaccination in Japan. Vaccines. 2021;9:48. https://doi.org/10.3390/vaccines9010048.

22. Lewis JR. What is driving the decline in people's willingness to take the COVID-19 vaccine in the United States? JAMA Health Forum. 2020;1:e201393.

23. Tyson A, Johnson C, Funk C. U.S. public now divided over whether to get COVID-19 vaccine, September 17, 2020. Pew Research Center. https:// www.pewresearch.org/science/2020/09/17/u-s-public-now-dividedover-whether-to-get-covid-19-vaccine/. Accessed 7 Apr 2021.

24. The Conversation. Americans have unrealistic expectations for a COVID19 vaccine, January 14, 2021. 2021. https://theconversation.com/ameri cans-have-unrealistic-expectations-for-a-covid-19-vaccine-152745. Accessed 7 Apr 2021.

25. Daly M, Robinson E. Willingness to vaccinate against COVID-19 in the US: longitudinal evidence from a nationally representative sample of adults from April-October 2020. medRxiv. 2020. https://doi.org/10.1101/2020.11. 27.20239970

26. Bartsch SM, O'Shea KJ, Ferguson MC, Bottazzi ME, Wedlock PT, Strych $U$, et al. Vaccine efficacy needed for a COVID-19 coronavirus vaccine to prevent or stop an epidemic as the sole intervention. Am J Prev Med. 2020;59:493-503. https://doi.org/10.1016/j.amepre.2020.06.011.

27. Torjesen I. Covid-19: Norway investigates 23 deaths in frail elderly patients after vaccination. BMJ. 2021;372:n149. https://doi.org/10.1136/ bmj.n149.

28. Taraldsen LE. Norway raises concern over vaccine jabs for the elderly, January 16, 2021. Bloomberg. 2021. https://www.bloomberg.com/news/ articles/2021-01-16/norway-vaccine-fatalities-among-people-75-andolder-rise-to-29. Accessed 7 Apr 2021.

29. Lorini C, Santomauro F, Donzellini M, Capecchi L, Bechini A, Boccalini S, et al. Health literacy and vaccination: a systematic review. Hum Vaccine Immunother. 2018;14:478-88. https://doi.org/10.1080/21645515.2017. 1392423.

30. Larson HJ, Clarke RM, Jarrett C, Eckersberger E, Levine Z, Schulz WS, et al. Measuring trust in vaccination: a systematic review. Hum Vaccine Immunother. 2018;14:1599-609. https://doi.org/10.1080/21645515.2018.14592 52.

31. Steens A, Stefanoff P, Daae A, Vestrheim DF, Bergsaker MA. High overall confidence in childhood vaccination in Norway, slightly lower among the unemployed and those with a lower level of education. Vaccine. 2020;38:4536-41. https://doi.org/10.1016/j.vaccine.2020.05.011.

32. WHO. Safety of COVID-19 vaccines. https://www.who.int/news-room/ feature-stories/detail/safety-of-covid-19-vaccines. Accessed 31 Mar 2021. 
https://www.who.int/news-room/feature-stories/detail/safety-of-covid19-vaccines. Accessed 11 July 2021.

33. Amit S, Regev-Yochay G, Afek A, Kreiss Y, Leshem E. Early rate reductions of SARS-CoV-2 infection and COVID-19 in BNT162b2 vaccine recipients. Lancet. 2021;397:875-7. https://doi.org/10.1016/S0140-6736(21)00448-7.

34. Haas EJ, Angulo FJ, McLaughlin JM, Anis E, Singer SR, Khan F, et al. Impact and effectiveness of mRNA BNT162b2 vaccine against SARS-CoV-2 infections and COVID-19 cases, hospitalisations, and deaths following a nationwide vaccination campaign in Israel: an observational study using national surveillance data. Lancet. 2021;397:1819-29. https://doi.org/10. 1016/S0140-6736(21)00947-8.

35. BBC News. Coronavirus vaccine: China jab $86 \%$ effective, UAE says, December 9, 2020. 2020. https://www.bbc.com/news/world-middleeast-55250560. Accessed 8 Apr 2021.

36. BBC News. Covid: what do we know about China's coronavirus vaccines? January 14, 2021. 2021. https://www.bbc.com/news/world-asia-china55212787. Accessed 8 Apr 2021

37. Ledford H. Six months of COVID vaccines: what 1.7 billion doses have taught scientists. Nature. 2021. https://www.nature.com/articles/d41586021-01505-x. Accessed 11 July 2021

38. Doria-Rose N, Suthar MS, Makowski M, O'Connell S, McDermott AB, Flach $B$, et al. Antibody persistence through 6 months after the second dose of mRNA-1273 vaccine for Covid-19. N Engl J Med. 2021;384:2259-3226. https://doi.org/10.1056/NEJMc2103916.

39. McAuley AJ, Kuiper MJ, Durr PA, Bruce MP, Barr J, Todd S, et al. Experimental and in silico evidence suggests vaccines are unlikely to be affected by D614G mutation in SARS-CoV-2 spike protein. NPJ Vaccines. 2020;5:96101. https://doi.org/10.1038/s41541-020-00246-8.

40. Liu Y, Liu J, Xia H, Zhang X, Fontes-Garfias CR, Swanson KA, et al. Neutralizing activity of BNT162b2-elicited serum. N Engl J Med. 2021;384:1466-8. https://doi.org/10.1056/NEJMc2102017.

41. Edara W, Hudson WH, Xie X, Ahmed R, Suthar MS. Neutralizing antibodies against SARS-CoV- 2 variants after infection and vaccination. JAMA. 2021;19:e214388. https://doi.org/10.1001/jama.2021.4388.
42. Zani A, Caccuri F, Messali S, Bonfanti C, Caruso A. Serosurvey in BNT162b2 vaccine-elicited neutralizing antibodies against authentic B. 1, B. 1.1. 7 , B. 1.351, B. 1.525 and P. 1 SARS-CoV-2 variants. Emerg Microbes Infect. 2021;10:1241-3. https://doi.org/10.1080/22221751.2021.1940305.

43. Haidere MF, Ratan ZA, Nowroz S, Zaman SB, Jung YJ, Hosseinzadeh H, et al. COVID-19 vaccine: critical questions with complicated answers. Biomol Ther. 2021;29:1-10. https://doi.org/10.4062/biomolther.2020.178.

44. Abbasi J. COVID-19 and mRNA vaccines-first large test for a new approach. JAMA. 2020;324:1125-7. https://doi.org/10.1001/jama.2020. 16866.

45. Doshi P. Will covid-19 vaccines save lives? Current trials aren't designed to tell us. BMJ. 2020;371:m4037. https://doi.org/10.1136/bmj.m4037.

46. Freeman D, Waite F, Rosebrock L, Petit A, Causier C, East A, et al. Coronavirus conspiracy beliefs, mistrust, and compliance with government guidelines in England. Psychol Med. 2020. https://doi.org/10.1017/S0033 291720001890

47. Chauhan G, Madou MJ, Kalra S, Chopra V, Ghosh D, Martinez-Chapa SO. Nanotechnology for COVID-19: therapeutics and vaccine research. ACS Nano. 2020;14:7760-82. https://doi.org/10.1021/acsnano.0c04006.

48. Chung YH, Beiss V, Fiering SN, Steinmetz NF. COVID-19 vaccine frontrunners and their nanotechnology design. ACS Nano. 2020;14:12522-37. https://doi.org/10.1021/acsnano.0c07197.

49. Le TT, Andreadakis Z, Kumar A, Román RG, Tollefsen S, Saville M, et al. The COVID-19 vaccine development landscape. Nat Rev Drug Discov. 2020;19:305-6. https://doi.org/10.1038/d41573-020-00073-5.

50. Aziz NA, Corman VM, Echterhoff AK, Müller MA, Richter A, Schmandke A, et al. Seroprevalence and correlates of SARS-CoV-2 neutralizing antibodies from a population-based study in Bonn, Germany. Nat Commun. 2021:12:1. https://doi.org/10.1038/s41467-021-22351-5.

51. He Z, Ren L, Yang J, Guo L, Feng L, Ma C, et al. Seroprevalence and humoral immune durability of anti-SARS-CoV-2 antibodies in Wuhan, China: a longitudinal, population-level, cross-sectional study. Lancet. 2021;397:1075-84. https://doi.org/10.1016/S0140-6736(21)00238-5.
Ready to submit your research? Choose BMC and benefit from:

- fast, convenient online submission

- thorough peer review by experienced researchers in your field

- rapid publication on acceptance

- support for research data, including large and complex data types

- gold Open Access which fosters wider collaboration and increased citations

- maximum visibility for your research: over 100M website views per year

At BMC, research is always in progress.

Learn more biomedcentral.com/submissions 